\title{
"CARACTERIZAÇÃO DO MOSTO CERVEJEIRO E DO MEL ORIUNDO DO SEMIÁRIDO BAIANO PARA PRODUÇÃO DE CERVEJA. "
}

\author{
Flávia Santana Santos ${ }^{1}$; Giovani Brandão Mafra de Carvalho²; \\ José Francisco Teles de Santana Júnior ${ }^{3}$ \\ 1. Bolsista PROBIC/UEFS, Graduando em Engenharia de Alimentos, Universidade Estadual de Feira de Santana, e- \\ mail: santos_flavinha1996@hotmail.com \\ 2. Orientador, Departamento de Tecnologia, Universidade Estadual de Feira de Santana, e-mail: \\ gbmafra@yahoo.com.br \\ 3. Participante do projeto, Departamento de Tecnologia, Universidade Estadual de Feira de Santana, e-mail: \\ juniorteles95@hotmail.com
}

PALAVRAS-CHAVE: mel, fermentação, Semiárido Baiano.

\section{INTRODUÇÃO}

O incentivo para se trabalhar com o mel do semiárido baiano foi de ter um mel puro e para agregar maior valor ao produto da região, gerando renda para os apicultores, além de preservar as plantas nativas. Outro fator importante é tentar baratear um processo considerado caro como é o cervejeiro. O principal objetivo do trabalho é caracterizar o mosto puro malte utilizado no processo cervejeiro e caracterizar o mel do semiárido baiano e avaliar se o mesmo possui características que venham a favorecer a sua utilização como adjunto de malte, para a produção de cervejas não convencionais.

\section{MATERIAL E MÉTODOS OU METODOLOGIA (ou equivalente)}

\section{Obtenção do mel.}

O mel do Semiárido Baiano vai ser obtido através de pequenos produtores da região ou feiras livres da cidade de Feira de Santana.

\section{Obtenção do mosto cervejeiro.}

Preparar o mosto frutado conforme metodologia desenvolvida por CARVALHO, 2009.

\section{Caracterização do mel e do Mosto Cervejeiro.}

Caracterizar o mel e o mosto cervejeiro quanto aos seguintes parâmetros: $O$ teor de umidade, extrato, sacarose, acidez (livre, lactônica e total), açúcares redutores (AR) e açúcares redutores totais (ART) (COPERSUCAR, 2001), pH (determinado diretamente pelo pHmetro digital); sólido solúveis totais (SST), determinado por leitura direta em refratômetro digital (Reichert, model AR200), carboidratos totais, através do método de Fenol Sulfúrico através da metodologia de Dubois et al., (1956) e açúcares redutores segundo Nelson (1944). E conforme (IAL, 1985), serão determinados acidez total titulável (ATT) pelo método titulométrico com solução padronizada de $\mathrm{NaOH} 0,1 \mathrm{~N}$; cinzas, através da calcinação das amostras a $550^{\circ} \mathrm{C}$; umidade, pelo método da estufa sob pressão reduzida a $70^{\circ} \mathrm{C}$ até peso constante; lipídeos, através da extração realizada pelo método Soxhlet; e proteínas, pelo método de Kjeldahl.

RESULTADOS E/OU DISCUSSÃO (ou Análise e discussão dos resultados) Caracterização do mel 
A caracterização físico-química do mel fornece um conhecimento prévio do teor de açúcares e a pureza da matéria prima. A Tabela 1 apresenta os resultados obtidos na caracterização físico-química do mel de abelhas (Apis melífera) que será utilizado como adjunto de malte na produção de cervejas não convencionais. A caracterização do mosto foi feita segundo a metodologia descrita pelo instituto Adolfo Lutz, 2008.

Tabela 1: Características físico-químicas do mel.

\begin{tabular}{c|cc}
\hline Parâmetros & Resultados & Legislação Brasileira \\
\hline Umidade $(\%)$ & $19,04 \pm 0,267$ & $<20$ \\
Sólidos Solúveis $\left({ }^{\circ}\right.$ Brix) & $80,00 \pm 0,133$ & NA \\
Acidez Total (meq/Kg) & $43,55 \pm 434$ & $<50$ \\
Açucares Redutores Totais & $71,12 \pm 0,657$ & $>65$ \\
(g/100g) & & \\
Sacarose (g/100g) & $4,78 \pm 0,55$ & NA \\
pH (adimensional) & $3,84 \pm 0,011$ & $<0,6$ \\
Cinzas (\%) & $0,12 \pm 0,017$ & - \\
Amido & NEGATIVO &
\end{tabular}

Os resultados demonstram que o mel que será utilizado como matéria prima para o desenvolvimento do estudo, na sua utilização como adjunto de malte, apresentou padrão de qualidade e identidade característico do mel puro de abelhas (Apis melífera), pois, o mesmo está de acordo aos limites estabelecidos pela Instrução Normativa número 11/2000 emitida pelo Ministério da Agricultura (BRASIL, 2000).

A umidade encontrada na amostra analisada obteve média de 19,04\% de umidade. A umidade do mel é influenciada pela concentração de extrato ( ${ }^{\circ}$ Brix). Quanto maior for a concentração de açucares, menor será seu teor de umidade. A umidade encontrada na amostra de mel analisada está de acordo com o esperado e dentro do padrão determinado pela legislação brasileira (BRASIL, 2000).

O mel analisado teve teor de sólidos solúveis igual a $80,00{ }^{\circ}$ Brix (Tabela 1), apresentando uma grande quantidade de açucares potencialmente adequada para $\mathrm{o}$ processo fermentativo da cerveja. É importante destacar que segundo Oliveira, Afonso e Costa (2011), este parâmetro é utilizado como medida indireta do teor de açúcares, uma vez que à medida que o teor de açúcares aumenta, ocorre simultaneamente uma elevação do teor de sólidos solúveis.

O teor médio de acidez das amostras foi de 43,55 meq/Kg (Tabela 1), resultado esse que se encontra abaixo do limite máximo da legislação para méis, que é de 50 $\mathrm{meq} / \mathrm{Kg}$. A acidez é importante na manutenção da estabilidade, reduzindo o risco de desenvolvimento de microrganismos (SEEMANN, 1988). É importante destacar que acidez é resultante dos ácidos orgânicos, que por sua vez têm influência na cor, sabor, odor e qualidade.

O conteúdo de açúcares redutores obtido na amostra de mel analisada obteve média de 71,12 g/100g (Tabela 1). Os principais açucares encontrados no mel são, glicose e a frutose, em proporções quase iguais (KERR, 1996), sendo importantes para o estabelecimento de uma série de características deste produto (MOREIRA, 2001).

O conteúdo de sacarose obtido na amostra de mel analisada obteve média de $4,78 \mathrm{~g} / 100 \mathrm{~g}$ (Tabela 1). As normas nacionais estabelecem máximo de $6 \%$, então, o resultado obtido encontra-se dentro dos parâmetros de qualidade exigidos para o mel.

O valor médio de $\mathrm{pH}$ obtido foi de 3,84 (Tabela 1). Os valores de $\mathrm{pH}$ não estão padronizados pela legislação nacional ou internacional. $\mathrm{O}$ valor de $\mathrm{pH}$ do mel pode ser 
influenciado pelo $\mathrm{pH}$ do néctar, solo ou associação de vegetais para composição do mel (CRANE, 1985).

O teor de cinzas obtido na amostra de mel analisada foi de $0,12 \%$ (Tabela 1). As normas nacionais estabelecem máximo de $0,6 \%$, então, o resultado obtido encontra-se dentro dos parâmetros de qualidade exigidos para o mel.

Para comprovar se ocorreu adulteração do mel foi feito o teste de Lugol. Esse teste tem como objetivo verificar se foi adicionado xaropes ao mel, no qual essa analise apresentou resultado negativo para adulteração do mel com xaropes que possam conter dextrinas e amido.

\section{Caracterização do mosto puro malte}

A caracterização do mosto foi feita segundo a metodologia descrita pelo instituto Adolfo Lutz, 2008.

Tabela 2: Caracterização físico-química do mosto cervejeiro, valores médios e desvio padrão.

\begin{tabular}{c|c}
\hline Características & Média \pm Desvio Padrão \\
\hline Umidade $(\mathbf{g} / \mathbf{1 0 0 g})$ & $90,86 \pm 0,0856$ \\
Cinzas $(\mathbf{g} / \mathbf{1 0 0 g})$ & $0,19 \pm 0,05$ \\
Proteína bruta $(\mathbf{g} / \mathbf{1 0 0 g})$ & $1,6 \pm 0,1693$ \\
Lipídios totais $(\mathbf{g} / \mathbf{1 0 0 g})$ & $1,9 \pm 0,2038$ \\
Carboidrato $(\mathbf{g} / \mathbf{1 0 0 g})$ & $16 \pm 0,05$ \\
Sólidos solúveis $\left({ }^{\mathbf{o}} \mathbf{B r i x}\right)$ & $12,5 \pm 0,01$ \\
Ph & $5,0 \pm 0,01$ \\
Acidez total titulável (meq NaOH/100g) & $1,5 \pm 0,01$ \\
Amido & NEGATIVO \\
\hline
\end{tabular}

A umidade de uma cerveja é influenciada pela concentração de extrato ( ${ }^{\circ}$ Brix). Quanto maior for a concentração do extrato do mosto, menor será seu teor de umidade. A umidade encontrada na cerveja analisada está de acordo o esperado para uma cerveja puro malte com $12^{\circ}$ Brix.

$O$ teor de cinzas da cerveja foi influenciado pelo extrato primitivo, normalmente cervejas do tipo puro malte apresentam maiores teores de cinzas do que cervejas que utilizam adjuntos. Esse comportamento é esperado, pois segundo Venturini Filho (1996), o malte é constituído por $1,97 \%$ de cinzas.

A proteína bruta da cerveja correspondeu a 1,6\%. De acordo com Briggs et al. (2004) ressaltam que o conteúdo de nitrogênio total multiplicado pelo fator 6,25 é frequentemente expresso como proteína. Normalmente as cervejas estão na faixa de $0,11-0,63 \%$ de proteínas. O valor encontrado está muito à cima da faixa apresentada pelos autores.

O resultado para lipídios totais foi 1,9\%. Conforme Azeredo (1999), estes compostos participam de muitas reações no metabolismo da levedura, por exemplo, contribuem na inibição da formação de ésteres de acetato durante o processo fermentativo.

O teor de carboidratos de uma cerveja é o que predomina para o seu valor energético, uma cerveja com elevado teor de carboidrato possui consequentemente um elevado valor energético. Esse grau de carboidrato de uma cerveja é oriundo do extrato primitivo da mesma.

A cerveja é um produto suavemente ácido, de forma que o malte de cevada clássica possui $\mathrm{pH}$ na faixa de 4-5 e a tipo "ale" variam de 3-6. O pH da cerveja 
analisada foi 5, o que adequado para uma cerveja tipo "ale". Durante o processo fermentativo o pH vai caindo. De acordo com Briggs et al. (2004), esta redução acontece enquanto os íons amônio e aminoácidos são consumidos pela levedura e os ácidos orgânicos são produzidos.

O resultado para acidez titulável foi 1,5, sendo que o adequado era que ele estivesse na faixa de $0,09-0,15 \%$ de acidez. É importante destacar que acidez é resultante dos ácidos orgânicos, que por sua vez têm influência na cor, sabor, odor e qualidade. Os ácidos orgânicos são importantes não somente por contribuir para o sabor e o aroma da cerveja, mas também por influenciar no $\mathrm{pH}$ de forma que um decréscimo durante a fermentação afeta as propriedades da cerveja.

A não presença de amido significa que todo ele foi convertido em açucares menores, que é o desejável para um mosto de boa qualidade. Resíduos de amido não degradado podem provocar problemas de fermentação, filtrabilidade, turbidez e estabilidade coloidal da cerveja pronta (Feistler 2014).

\section{CONSIDERAÇÕES FINAIS (ou Conclusão)}

Com o presente projeto de iniciação cientifica, pode-se concluir que a utilização da matéria prima, o mel oriundo do Semiárido Baiano como adjunto de malte na produção de cerveja, é viável, pois, o mesmo tem características que favorecem todo o processo fermentativo. Levando-se em consideração o fato de se tratar de um produto rico em açucares, o mel se torna um adjunto que vem a potencializar na obtenção do produto da fermentação (etanol e $\mathrm{CO}_{2}$ ), além de fornecer a cerveja, as características sensoriais desejáveis, é também uma matéria em abundancia na região.

\section{REFERÊNCIAS}

AZEREDO, M. A. A.; AZEREDO, L. da C.; DAMASCENO, J. G. Características físico-químicas dos méis do município de São Fidélis - RJ. Ciência e Tecnologia de Alimentos, v. 19, n. 1, p. 3-7, 1999.

BRASIL. Ministério da Agricultura, Pecuária e Abastecimento. Instrução Normativa 11, de 20 de outubro de 2000. Regulamento Técnico de identidade e qualidade do mel. Disponível em: <http://www.agricultura.gov.br/das/dipoa/anexo intrnorm11.htm>. Acesso em: jul. 2017.

Briggs M, Funge-Smith S, Subasinghe R, Phillips M (2004) Introductions and movement of Penaeus vannamei and Penaeus stylirostris in Asia and the Pacific. Food and Agriculture Organization of the United Nations, Regional Office for Asia and the Pacific. RAP Publication 2004.

CRANE, E. O livro do mel. $2^{a}$ edição. São Paulo: Nobel, 1985.

FEISTLER, O. 2014. “Apostila Operador Cervejeiro-AMBEV”. Porto Alegre.

HORN, H. Méis Brasileiros: resultados de análises físico-químicas e palinológicas. In: XI Congresso Brasileiro de Apicultura, Teresina, PI, 1996. p. 403-429.

KERR, W.E. Biologia e manejo da Tiúba, a abelha do Maranhão. São Luís: Edufma, 1996. $156 \mathrm{p}$.

PAMPLONA, B. C. Exame dos elementos químicos inorgânicos encontrados em méis brasileiros de Apis mellifera e suas relações físico-biológicas. São Paulo, 1989.131 p. Dissertação (Mestrado) - Instituto de Biologia, Universidade de São Paulo (USP).

MOREIRA, R. F. A.; MARIA, C. A. B de. Glicídios no mel. Química Nova, v. 24, n. 4, p. 516-525, 2001.

SEEMANN, P.; NEIRA, M. Tecnología de la producción apícola. Valdivia: Universidad Austral de Chile, Facultad de Ciencias Agrarias Empaste, 1988. 